\title{
INVITATION AND GUIDELINES FOR AUTHORS
}

AJMR invites research papers, abstracts of doctoral dissertations and major research project reports, case studies, book reviews and student articles from academicians, professionals and students. The following are the guidelines for the contribution.

The contribution must be original in nature and should neither be published nor under consideration for publication anywhere else.

The manuscript including figures, tables and references should be around 15 typed pages for Research Papers: four pages for abstracts of doctoral dissertations and research project reports: six pages for case studies: two pages for book reviews and six pages for student articles. All the manuscripts should clearly be typed in double space with 12 point font size.

\section{For submission:}

* COVERING LETTER: Title of the paper, Authors Name, Designation, Organization, Official Address, Personal Address. Contact Number (Official \& Personal) and E-mail address. 'ABSTRACT: Should contain in brief-objective, Research Question / Hypothesis, Methodology, Finding and 5-6 keywords.

Word Limit: $250-300$ words

*FULL PAPER

- Format: A-4 Size, MS-Word

- Word Limit: Not to exceed 5000 words

- Font: Times New Roman

- Font Size: Heading -14, Text-12

- Margin: 1.5-inch on all four sides

- Line Spacing: 1.5

\section{Format of the paper:}

- Title : Title should not be more than 6-8 words

- Definitions : Paper should be clear and concise with proper definitions for specialized terms.

- Sections: Introduction. Objectives, Research Question/Hypothesis, Methodology Findings/Results, Conclusion/Recommendations and Limitations, 5-6 Key Words.

- Annexure : Tables. Charts. Graphs, Quotations, Equations, Articles should be numbered, cited and referenced properly.

- Abbreviations : Any Abbreviations used should be written in full at first followed by the abbreviations in the parenthesis.

- Referencing : The Harvard System should be used in referencing.

- Foot Notes : Should be numbered consecutively in the text and should be typed on same page they are denoted. 
Declaration : Author must declare originality of work. The article should not have been published or be submitted for publication elsewhere.

- The contributions sent for publication may be referred for review.

- Correspondence and proofs for correction, if required, will be sent to the first named authors.

- Unless otherwise indicated, corrected proofs should be returned within 10 days.

The final decision on the acceptance or otherwise of the paper rests with the editorial board and it depends entirety on its standard and relevance. The final draft may be subjected to editorial amendment to suit the requirements of the journal. The decision about acceptance or otherwise of the paper will be conveyed to the author within 60 days.

The Journal neither charges any processing fee nor pays any honorarium to the authors. Editorial decisions will be communicated within a period of maximum two months of receipt of articles. Author will receive one complimentary copy of the journal. Editorial Board's decision will be final.

The copyright of all accepted papers will vest with AJMR.

Soft copy of the manuscripts are to be sent to:

anithar72@yahoo.com

or

sumangalatalur@yahoo.com 